\title{
Risks and Rewards of Small System Integration into a Detailed Maintenance System
}

\author{
Brian Fitzpatrick $^{1, *}$, Paul Herrington ${ }^{1}$, Syed Adeel Ahmed ${ }^{2}$ \\ ${ }^{1}$ Engineering Management at the University of New Orleans \\ ${ }^{2}$ Xavier University of Louisiana \\ *Corresponding Author: bdfitzpa@my.uno.edu
}

Copyright (C) 2013 Horizon Research Publishing All rights reserved.

\begin{abstract}
The expectation of the Coast Guard from a mission execution standpoint is that the Coast Guard is "Semper Paratus - Always Ready" meaning that the physical asset and crew are ready to launch on a mission at any given time. The meaning for the mission support infrastructure and the greater engineering and logistics organization of the Coast Guard is that no matter how the boat, ship, or aircraft were acquired, it must be supported to the same degree of operational readiness. Therefore the same level of support is required for the helicopter as the ship it lands on, and the small boat that is used to transport a boarding party. While the helicopter and the ship are both major systems acquisitions and follow a strict process and generally garner high levels of support and oversight, the small boat that delivers the boarding party to another vessel most likely was procured through the non-major acquisitions process classified as a procurement action. Even though the acquisition strategies used to procure each asset was very different, each asset is expected to reach the same level of engineering, logistics, and supply support.
\end{abstract}

Keywords Fleet Logistics System, Coast Guard, Department of Homeland Security, Computerized Maintenance System, Small System Acquisitions, Project/Program Management

\section{Introduction}

The United States Coast Guard unified the acquisition of all small boats to be procured under one directorate in order to standardize and streamline the purchase of Coast Guard small boats stationed throughout the country and around the world. Coast Guard small boats are involved in over 70 percent of all Coast Guard operational missions and number just shy of 2,000 boats of approximately 25 different classes. The boats and crews complete missions ranging from search and rescue, marine environmental protection, aids to navigation, maritime port security, and defense operations. The boats are supported by one single division of the Surface
Forces Logistics Center (SFLC) providing configuration management, total asset visibility, bi-level maintenance, and single point of accountability [1]. In order to prepare for accepting new asset classes into the fleet as completely supported assets, multiple years of preparation are generally needed to achieve full level support. However a streamlined process is necessary to execute non-major acquisitions due to condensed timelines on the order of months for each acquisition project.

The non-major acquisition process is a formalized process that allows federal agencies to procure assets below the threshold with approval of the agency's acquisition executive. The process streamlines the cost overhead on the government, often limits the deliverables, and condenses timelines [6]. The condensed timelines are due to federal appropriations budgets and fiscal year constraints; hence non-major acquisitions are often funded out of annual budgets versus multi-year construction and infrastructure (AC\&I) budgets, due to their lower dollar value and in an effort to reduce overhead costs. The effect of the abbreviated schedule on the boat builder reduces the design to production time to two to three months verses six to ten months. Often the end result for the boat builder is that the boat is already in some form of construction, even while completing the design phase of the craft. The asset manager takes over the verification and validation of the provisioning and technical data, as the subject matter expert and eventual engineering and logistical support entity. The program manager fills the role as contracting officer technical representative, warranty officer, and project manager for the acquisition.-

The Coast Guard's logistics model was developed by the aviation community for the support of its airframes, both fixed and rotary, and adapted to the support of the naval community. Many of the assumptions in the development of the logistics model were contingent on having a major acquisition base and full asset project office, before the first airframe reached an operational unit. This is not the case for small boat acquisitions, where the acquisition strategy is very different, and the expense of creating an asset project office prohibitive. Small boat production timelines are shorter in comparison to aircraft which are measured in 
months; small boats are generally measured in weeks and larger numbers are delivered. Acquisition of 150 small boats in a year is not unheard of, while this number would replace all short-range rescue helicopters in the Coast Guard inventory one and a half times. The aviation process is to take an airframe, place it in a hanger where it is tested, and experienced technicians maintain it while the logistics package is developed. This process is expensive, time consuming, and labor intensive. Only after the logistics package is developed are the new airframes delivered to multiple locations, thereby minimizing the operational risk. The inherent risk in flight is much greater and the systems are more complex than those of a small boat, but the customer or the vessel in distress expects that the airframe or boat sent to save them will be ready in their time of need. A process was designed to develop a small boat logistics package from a non-major acquisition and induct it into the Coast Guard logistics system, without incurring major expenses of creating a project office, and without the benefit of having a boat or a large project office outside of the SFLC Small Boat Product Line [3]. The process was developed by trial and error over a three year period with multiple non-major small boat acquisitions.

Latent effects of a poor acquisition and poor logistics strategy can cause the loss of a class of vessel due to class-wide technical problems in post-delivery. These technical problems can bring an entire theater of operations to a standstill, meaning the vessel's mission will have to be executed by a secondary or tertiary means. In many cases, the alternatives are too slow or too far away to provide meaningful assistance and the rescue operation becomes a recovery operation. The need to acquire and maintain the best possible assets by the most cost effective means possible is the mission of the Coast Guards acquisition and support professionals.

\section{Delivery and Review of Provisioning and Technical Data}

To insure response asset readiness for search and rescue and law enforcement missions, the Coast Guard has set asset operational availability requirements for each asset class. The asset availability is based on the need to complete organizational level maintenance (maintenance completed by Operational Unit level personnel), order supplies, complete depot level maintenance (maintenance completed by anyone outside of the operational unit), and accounts for unscheduled maintenance or repairs. In order to develop the non-major acquisition into a fully supported asset, the logistics and technical data must be refined through a validation and development process. This process is as critical as delivering the physical asset to the end user. All logistics preparation is completed concurrent with full rate production. The configuration of the vessel is "locked-down," or the boat builder cannot change the configuration of the vessel without Coast Guard approval, and technical data can be more easily validated with limited rework due to configuration changes.

The preliminary delivery of the provisioning and technical data is the first point in which the Coast Guard will have to complete a through document review, ensuring that all information for the support of the vessel class is present. This data includes calculations for stability, electrical load, fuel consumption, engineering drawings, systems schematics, master equipment list, and technical manuals for specific equipment. The builder must also deliver a boat information book, which is essentially an owner's manual for the boat that outlines basic operations, builder recommended operating restrictions, safety equipment, and recommended maintenance that is not in the original equipment manufacturer's technical manual. Subject matter experts verify that all data is present and free of errors. Many commercial companies voice concerns about submitting the large amounts of information required, as producing the information typically requires many hours to produce. The information is extensive but necessary for the engineers and logisticians within the Coast Guard to build the configuration, procure spare parts, build a maintenance schedule, and support the new boat class for its entire lifecycle. After the preliminary review, a punch list is made for all discrepancies found in the data, from format and spelling to technical and mathematical calculations.

In an effort to control cost and schedule for both the Coast Guard and the boat builder, which in most cases are classified by the U.S. Department of Labor as small businesses, the communications concerning the provisioning and technical data is quick. Government comments are kept to a minimum and the contracting officer adjudicates all comments as either contractual or not. The process is kept to a minimum, as time is critical, with full rate production of the boat class waiting only for the positive completion of operational test and evaluation. The difference with large-scale major contracts is often the system being acquired is more complex, more technical data is generated by the contractor, and the contractor is more capable to perform logistics analyses than the small boat builder. After a second round of review by the government to verify that contractual discrepancies are corrected, a final configuration validation is completed on the first full rate production boat. At this point the boat builder will submit the provisioning and technical data for approval by the program manager.

\section{Process of Developing and Integrating into Logistics and Supply System}

The development project can begin when the provisioning and technical data are accepted; the initial goal for the asset manager is to induct the boats that have been delivered into a rudimentary system, in order to provide support for items that are not covered under the warranty purchased as part of 
the acquisition. To do this, the configuration of the boat must be built into two systems, the first being the fleet logistics system (FLS), which is one of two Coast Guard specific computer programs that stores class-based configuration data. Configuration data helps to identify systems and subsystems onboard the vessel with information such as original equipment manufacturer, model number, and part number. This information is taken directly from the master equipment list delivered by the contractor. By having each hull in the class entered into the FLS, the asset manager and staff members have a way to track basic maintenance history for depot repairs made during the warranty period and account for any funding expenditures. This essentially is an interim support step while the total logistics package is developed. The asset manager will also load electronic versions of the technical data into the technical information management system, allowing any depot or field technician throughout the Coast Guard to access the information, and protects it from being lost, maintain version control, and security protocols.

Concurrent to FLS induction, a maintenance requirements list is developed, which is a list of every maintenance procedure that is associated with the boat. All of these procedures are base lined from the deliverables in the provisioning and technical data; additions will be made where technical judgment makes sense for items such as hull corrosion inspections, mishap recovery/reporting, and other Coast Guard specific procedures that may not be covered in equipment manuals. The maintenance requirements list not only includes a listing by title; a periodicity is assigned, who completes the maintenance is assigned (organizational or depot), and a procedure number is assigned. The maintenance requirements list goes through several revisions as the unit operating the prototype boat identifies more tasks. The asset manager and a maintenance analyst develop the maintenance requirements list and both will use the list for different purposes.

The maintenance analyst will take the maintenance requirements lists and the master equipment list, and build the class configuration into the asset computerized maintenance system (ACMS). ACMS attaches the various pieces of equipment installed a boat class, and associates them within the database with the specific equipment's maintenance schedule. When the specifics boats schedule is entered into the system this becomes known as the Maintenance Requirements List. [2] The maintenance analyst will then build the configuration of each boat (boats are tracked by hull number in the Coast Guard) that includes the serial number and model of each major component. The selection of items to serial track a hull, machinery, and equipment item is based off two business decisions first is the item going to be enrolled in an overhaul or repair program that will require the equipment's enrollment in a pool, the second requirement for the equipment to be serial tracked is if the equipment is the dollar value. A pooling program has increased asset availability and decreased operating expenses; however there are certain capital expenses that increase with such a program. By serial tracking a piece of equipment the data management is such that the maintenance and repair information with the specific serial number can be looked up by any technician with access to the system. When the engine is repaired and goes back out to the fleet, most likely it will not go back to the same hull, but to a different hull at a different unit. The engineering department at that unit will also have the maintenance history of the engine via its serial number when the engine is installed on their hull. There are several manual interfaces within the computer program that the maintenance analyst has to complete to transfer the engine within the ACMS. If an item is not going to be repaired or managed in this way, it does not make sense to serial track the item, unless specifically required by regulations.

While the maintenance analyst builds entries into the ACMS program, the asset manager will develop the maintenance procedure cards. A best practice was found in order to start the tracking of maintenance completion as early on in the lifecycle as possible assigning and loading a sign off only maintenance procedures to ACMS and provides an initial operating capability of the maintenance system. These maintenance procedures will have what is known as a "Page 1, sign-off sheet." This sign off sheet will simply reference an owner's manual or technical publication with page number so that a field technician can find the procedure. At the field level, the technician will be able to look at page 1, then go into the technical information management system and pull the publication. This initial operating capability in ACMS allows for the start of maintenance data recording and the start of what will become large amounts of trend data. This process is depicted in Figure 1: Maintenance Development Process Flow, below. In some cases where this was not done, the inability to collect data for the year resulted in more expensive retrofits and repairs in the out years. There have also been cases where data was not collected for several months, resulting in trends not being recognized, a replace maintenance procedure card was not being entered because there was no system in place to track the data required for the recognition of the trend. Some of these repairs were due in part to the lack of maintenance and the lack of knowledge on the new boat by the field technician, basically because the technician did not know there was a requirement to perform a procedure, and simply did not complete the maintenance. By having a scheduling and tracking tool for the field technician, the end effect is increased knowledge and visibility of the maintenance, and a drop in downtime due to unscheduled repairs. 


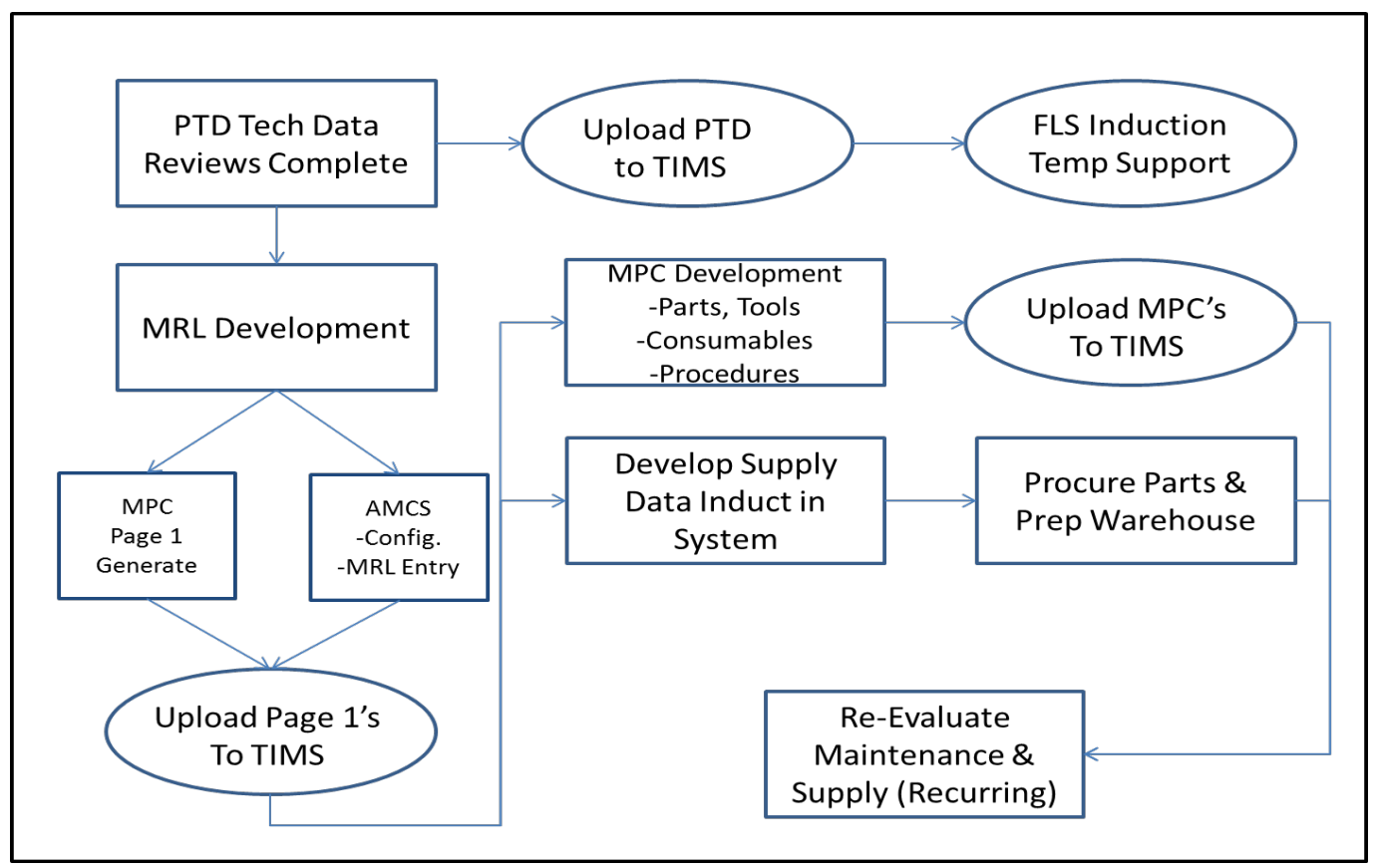

Figure 1. Maintenance Development Process Flow

The asset manager will then develop the maintenance procedure cards, and the Page 1's will be substantially increased in information. Rather than just simply a sign off referencing a technical publication, it will become a procedure with information on tools required, parts required, consumables, warning labels, and the procedure itself. In concert with this effort, the asset manager will develop the supply data, identifying the exact parts to be used and having the item manager create a stock number. This stock number is what becomes available for all parts that are procured in bulk for the units at the logistics center. These parts are then stocked in the warehouse and shipped to the individual units, thereby centralizing purchasing, and offers potential for lower costs by bulk purchasing. The procedures may be developed further, offering platform specific information, such as equipment removal procedures that protect sensitive electronics or controls. Others may simply be an excerpt from the technical publication that covers the procedure. This combination allows for the asset manager to decide, saving both time and funds, while preserving the integrity of the maintenance procedure.

When the second iteration of the procedures is complete, the deck is loaded to the technical information management system and hyperlinked in the asset computerized maintenance system. This hyperlink is directly from the maintenance due list for the specific hull number. The maintenance technician will then perform the maintenance procedure, sign the Page 1, and send to the data entry clerk. At this point, ACMS is tracking the maintenance performed on each boat, number of times a task was performed fleet wide, and the periodicity between a maintenance and repair activity being performed. This information is used in performing root cause failure analysis, adjusting the maintenance periodicity, and forecasting manpower.

\section{Linking the Maintenance with the Supply}

Once maintenance procedures are completed, all parts, tools, and consumables must be cataloged and identified within the supply system. Often with boat classes that use large amounts of commercial off the shelf (COTS) systems, the Department of Defense (DOD) Logistics system is not available due to not stocking the item. In this case the item must be identified and cataloged to create a national stock number, entered into both the Coast Guard's internal stock system and the DOD stock system. The items are then associated with the platform and maintenance procedures within the Coast Guard's stock system.

During the maintenance development process, the asset manager, working in coordination with an item manager and contracting officer, will identify equipment manufacturers and common parts to establish a procurement mechanism to stock the warehouse and provide supplies to the field units. The asset manager and item manger will develop the necessary sparing level based upon maintenance periodicity, projected operating hours, and estimated failure rates. The sparing model, based on periodicity and projected maintenance operating hours, is determined on an annual basis, and then broken into shorter periods of time. This is essentially the naïve approach of forecasting the amount of maintenance parts needed without system operating data. By analyzing number of boats produced in a given year, projected average operating hours, and the periodicity of the maintenance item gives the number of each item needed.

For casualty repair parts that are not part of the planned or scheduled maintenance, a purchasing plan based off the boats system attributes is developed to mitigate the asset downtime due to government procurement timelines. Items 
identified as potential high failure, critical to mission, or needed for safe operation. This enables the item manager to stock the specified items in the central warehouse and remove the delay in procurement time of the item from the repair time. Each part that is similar becomes a discussion, as it is also the responsibility of the asset manager to provide affordable readiness while being a steward of taxpayer funds. Therefore a high value part may be kept in the warehouse and not locally, and the risk of operational down is assumed in the cost saving effort. The asset manager also will not provide a part to a unit if a higher level of training or facility is required to affect the repair.

Attempting to predict supply levels for casualty repairs without robust repair history on the platform is based on educated guesses. Most asset managers are experienced technicians themselves, or are paired with an experienced technician with fifteen to thirty years of experience. By working with several experienced technicians and logistics professionals, a reasonable first solution for casualty sparing can be developed.

By being able to cross reference the maintenance, operations, and the supply system, tremendous savings can be found by adjusting the maintenance system to the boat class, operational environment, mission specific needs, and technical considerations. With the proper set up of the cross referenced data systems and the links between maintenance, supply, and operations the asset manager and maintenance analyst can identify technical problems that are either costing the Coast Guard money or lost operating time. This capability of the logistics and engineering system is only achievable through having the correct level of data.

Without having the logistics system information developed, the Coast Guard would be incapable of monitoring the operational availability of its assets, as well as monitoring the total lifecycle cost of those assets. If this capability is removed, any ability to reduce total lifecycle cost of a particular asset class is greatly reduced. The upfront investment in both manpower and funding is required, however the ability to control maintenance and repair costs without a loss in operational availability is paramount to the overall operational mission of the Coast Guard while still being good financial stewards of taxpayer dollars.

\section{Conclusion}

The ability to control costs and still effectively execute the mission is dependent on the management of the organization. The Coast Guard's small boat fleet has met the operational readiness requirements set by the Assistant Commandant for Capability over the course of the past four years and been able to reduce operating and maintenance costs via consolidation of the engineering and logistics infrastructure coupled with solid management practice. The non-major acquisitions combined with the logistics support in the Coast Guard have offered the agility required by the operational commanders throughout the world to respond to such national disasters as the Haiti Earthquake, Deepwater Horizon Oil Spill, and Hurricane Sandy. The flexibility to provide the proper assets to safely operate and execute in an ever changing maritime environment will required new boats with new technologies at an affordable cost.

The adoption of providing an initial support plan to support an initial operating capability that also captures key maintenance and cost data can pay dividends for future major acquisitions by simply scaling up from the baseline plan described here. The initial investment in the logistics infrastructure by the Coast Guard has allowed attaining affordable readiness for the small boat fleet. The effectiveness of the small boat program has been proven to reduce maintenance costs between 30 to 50 percent as compared to previous U.S. Coast Guard Logistics models. [4] While not totally due to the development of logistics plans but due to the problems identified by the logistics plan and acted upon the asset manager.

As described by the Commandant of the Coast Guard Admiral Robert Papp, sizeable portions of the Coast Guard's focus will be to the artic. The artic holds new logistical challenges for the Coast Guard, namely the ability to operate and maintain vessels in areas with sub-zero temperatures that have greater potential for equipment damage not normally seen in current areas that see large Coast Guard operations [5]. Specialized small boats will be required to support the increased operations in this remote theater and thus increased engineering and logistics presence will be required to support and sustain the theater of operations. The remoteness of the artic and the problem of overcoming longer supply routes and lead times will become an issue, which creative logisticians and maintenance planners will overcome. This new theater of operations provides new challenges to engineering and logistics execution the lack of infrastructure for communications and industrial work as well as the distances between operating locations will all play impacts on the asset availability and the ability to support the increase of operations within the arctic theater. As the logisticians and engineers learn more about the boats operating in the artic and its environment, costs will be high and difficult to control.

The mission support and logistics infrastructure must be at the lead of every new operating challenge the Coast Guard faces, from the start of a new acquisition, to the planning of entering a new theater of operations. The need to control costs of operations from the front end, by developing a complete technical and logistics support information package, providing asset visibility, and supply parts at the lowest possible cost, will be paramount.

The views expressed herein are those of the author and are not to be construed as official or reflecting the views of the Commandant or of the U. S. Coast Guard.

\section{REFERENCES}

[1] Currier, John L. Mission Support 2.0 Cornerstone Document. United States Coast Guard. Washington, DC. 
2010.

[2] Keister, Scott A. Small Boat Product Line Standard Operating Procedure. United States Coast Guard. Baltimore, MD. 2012.

[3] Lebeau, M. P. et al. Product Line Standard Operating Procedure. United States Coast Guard. Baltimore, MD. 2011

[4] Marcario, John. "The Small Boat Challenge" SeaPower
Volume 53, Number 12. Navy League, Washington, DC. 2010.

[5] Papp, Robert J. The U. S. Coast Guards Vision for Operating in the Arctic Region. United States Coast Guard. Washington, DC. 2013.

[6] Rabago, R. J. Major Systems Acquisition Manual, COMDTINST M5000.10B. United States Coast Guard. Washington, DC. 2010. 